SPECIAL SECTION:

CONSERVATION IN PRACTICE

\title{
Integrating farmer input and Agricultural Conservation Planning Framework results to develop watershed plans in lowa
}

Karl Gesch, Adam Kiel, Todd Sutphin, and Roger Wolf

$\mathrm{T}$ he state of Iowa is a national leader in applying the watershed approach to improve water quality. In addition to protecting and improving local water resources, this effort is inspired by calls from the United States Environmental Protection Agency (USEPA) for states in the Mississippi River Basin to reduce hypoxia in the Gulf of Mexico (Stoner 2011; Beauvais 2016). The Iowa Nutrient Reduction Strategy (INRS) was released in 2013 to establish a framework for reducing nitrogen $(\mathrm{N})$ and phosphorus (P) loads to Iowa and downstream surface waters (IDALS et al. 2017).

The INRS provides flexibility to local watershed stakeholders to identify appropriate ways to organize and implement conservation practices that reduce nutrient loss. To best accomplish this, the Iowa Soybean Association (ISA) - along with its farmer members and partner organizationssupports use of planning, implementation, and evaluation at the scale of 12-digit hydrologic unit code (HUC12) watersheds. Many HUC12 watersheds in Iowa are composed primarily of agricultural land (93\%) or contain no point sources prioritized within the INRS (93\%). These small, rural watersheds are the current scale and focus of most INRS-focused watershed projects in Iowa. To achieve INRS goals, the state of Iowa must transition from demonstration HUC12 watershed projects to full-scale, statewide implementation of the strategy. The INRS promotes a flexible, voluntary approach to reducing agricultural nutrient loading. As such, there is a need to create enabling conditions for broad increases in conservation adoption within the context of the watershed approach. Watershed planning has been and will continue to be a critical component of this effort.

The ISA engages farmers and landowners in watershed programming and conservation initiatives. In many cases, past and ongoing water monitoring and applied research bolster farmer interest and support for watershed plan development.

\section{Figure 1}

Farmers, landowners, and local stakeholders provide insights and feedback at a watershed planning community input session (Photo credit: Joseph L. Murphy/lowa Soybean Association).

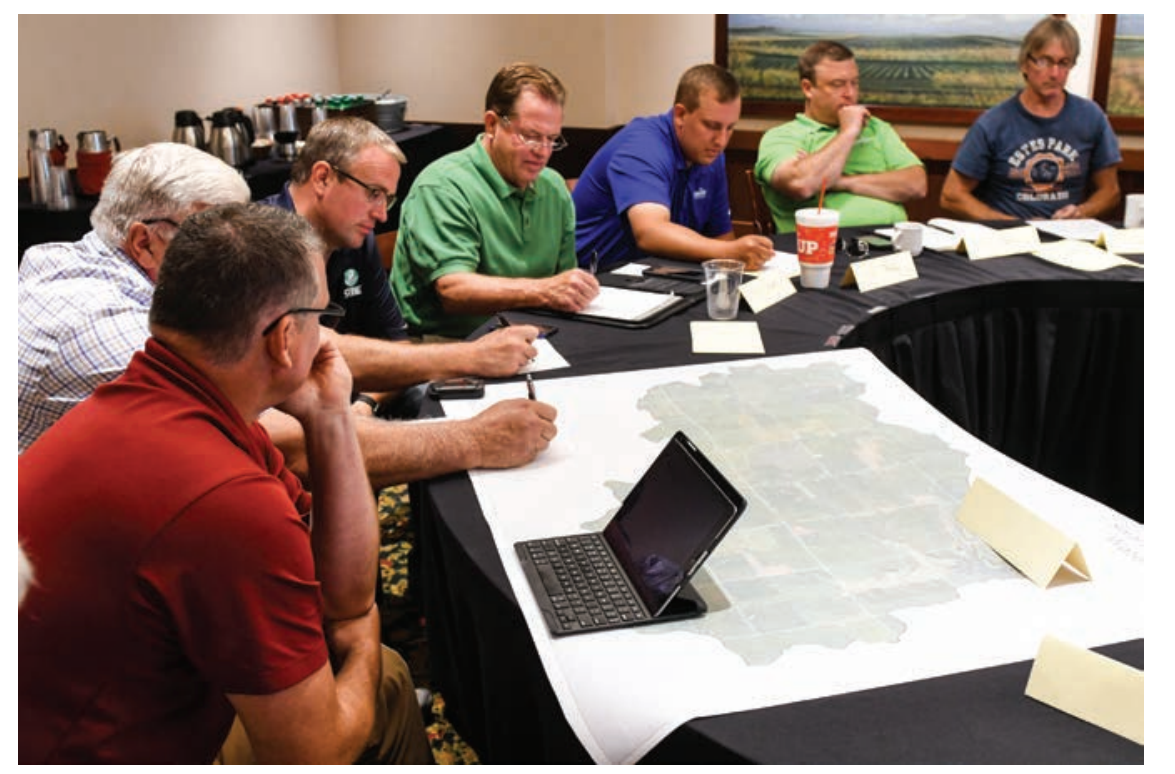

Additionally, monitoring and research inform adaptive management strategies by farmers and partners as watershed projects are implemented. The ISA strives to advance the INRS by working with small groups of farmers and community leaders to develop HUC12 watershed-scale plans. These watershed plans identify local priorities, implementation objectives, and potential locations for conservation practice adoption. Furthermore, the ISA substantially involves farmers and landowners throughout the watershed planning process to cultivate local awareness, buy-in, and leadership. The overall goals of supporting farmers through watershed planning are to accelerate implementation of the INRS and empower long-term, farmer-led success in water quality improvement.

ISA watershed plans are developed according to Iowa Department of Natural Resources recommendations, which are structured to address the USEPA nine minimum elements of watershed plans (IDNR 2009). Within this framework, the ISA works with farmers to establish high priority local issues, objectives, and locations within small, agricultural watersheds. Priorities are identified through farmer and landowner input. Objectives are set through simple water quality modeling. Potential sites for conservation practice construction are identified with the Agricultural Conservation Planning Framework (ACPF) software (Tomer et al. 2015; Porter et al. 2018). The basic recipe for socially acceptable, geographically robust plans is farmer input plus water quality modeling plus ACPF results.

Priorities answer the "what" questions: what are the goals and what can be done to address them? The opportunity to develop, adopt, and mobilize around a set of common goals can initiate and build momentum for a watershed proj-

Karl Gesch is a project manager, Adam Kiel is operations manager of water resources, Todd Sutphin is senior operations manager, and Roger Wolf is director of environmental programs and services at the lowa Soybean Association, Ankeny, lowa.

Received February 26, 2019; Published online April 25, 2020. 
ect. ISA watershed planning facilitators gather farmer and landowner input, values, and preferences through community input sessions and individual outreach (figure 1). These contributions are used to develop goal statements and to prioritize conservation practices that can address the locally defined goals. For example, farmers and landowners in the Headwaters Cedar Creek watershed located primarily in Pocahontas County, Iowa (figure 2), participated in the watershed planning process during 2016. Farmers set goals to reduce nonpoint source $\mathrm{N}$ and $\mathrm{P}$ loads to levels specified in the INRS. The group of farmers also identified priority conservation practices including wetlands, saturated buffers, cover crops, and more. The locally established goals and priorities gave focus to the remaining components of the watershed plan.

Objectives clarify the "how much" question: how much adoption and implementation will be needed to meet watershed goals? With farmer-driven priorities as a starting point, a watershed plan should recommend specific levels of conservation practices that are necessary to meet watershed goals. To identify adequate and appropriate implementation targets, ISA watershed planners develop water quality models. The models are designed to be quantitative, simple, and science-based. Therefore, water quality modeling is based on the "Iowa Science Assessment of Nonpoint Source Practices to Reduce Nitrogen Transport in the Mississippi River Basin" (section 2.2 of the INRS). Water quality models are used to assemble hypothetical scenarios of future conservation practice adoption within the watershed. These scenarios identify potential combinations of conservation practices (as prioritized by farmers) that can reasonably be expected to meet watershed goals (as set by farmers). Just as the INRS nonpoint science assessment illustrates statewide scenarios that could achieve nutrient reduction goals, this application of local prioritization in conjunction with basic water quality modeling is used to demonstrate locally acceptable and feasible (albeit ambitious) scenarios to achieve similar goals at the scale of individual HUC12 watersheds.
Locations address the "where" question: where in the watershed might priority conservation practices be installed? In addition to being locally driven and quantitative, watershed plans should identify locations within the watershed where priority conservation activities may be appropriate. This deepens the placedbased approach to watershed planning: goals are established to meet perceived and actual local needs, and specific potential locations are identified via soils, land use, and topographic data. The ACPF watershed characterization and practice siting tools leverage the immense potential of these high-resolution geospatial datasets to add an element of spatial specificity to watershed planning. This precision is invaluable from a planning perspective and readily deployable as an outreach tool. It is important to remember that the ACPF geographic information system tools are not intended to prioritize among practices or locations. However, the ACPF conservation pyramid (Tomer et al. 2013) provides a conceptual approach for prioritizing practices, quantities, and locations as watershed plans are configured.

Locally prioritized practices, sciencebased implementation objectives, and ACPF-derived locations are integrated to develop watershed conceptual plans. In the case of the Headwaters Cedar Creek Watershed Plan (ISA 2016), farmers approved a scenario that identified a combination of wetlands, saturated buffers, bioreactors, and drainage water management (each identified using ACPF siting tools) along with in-field management practices including $\mathrm{N}$ management,

\section{Figure 2}

The Headwaters Cedar Creek watershed (HUC12 number 071000060202) is located in Pocahontas, Buena Vista, Clay, and Palo Alto counties in lowa. The watershed is 14,134 ha $(34,925 \mathrm{ac})$, approximately $85 \%$ of which are used for row crop agriculture.

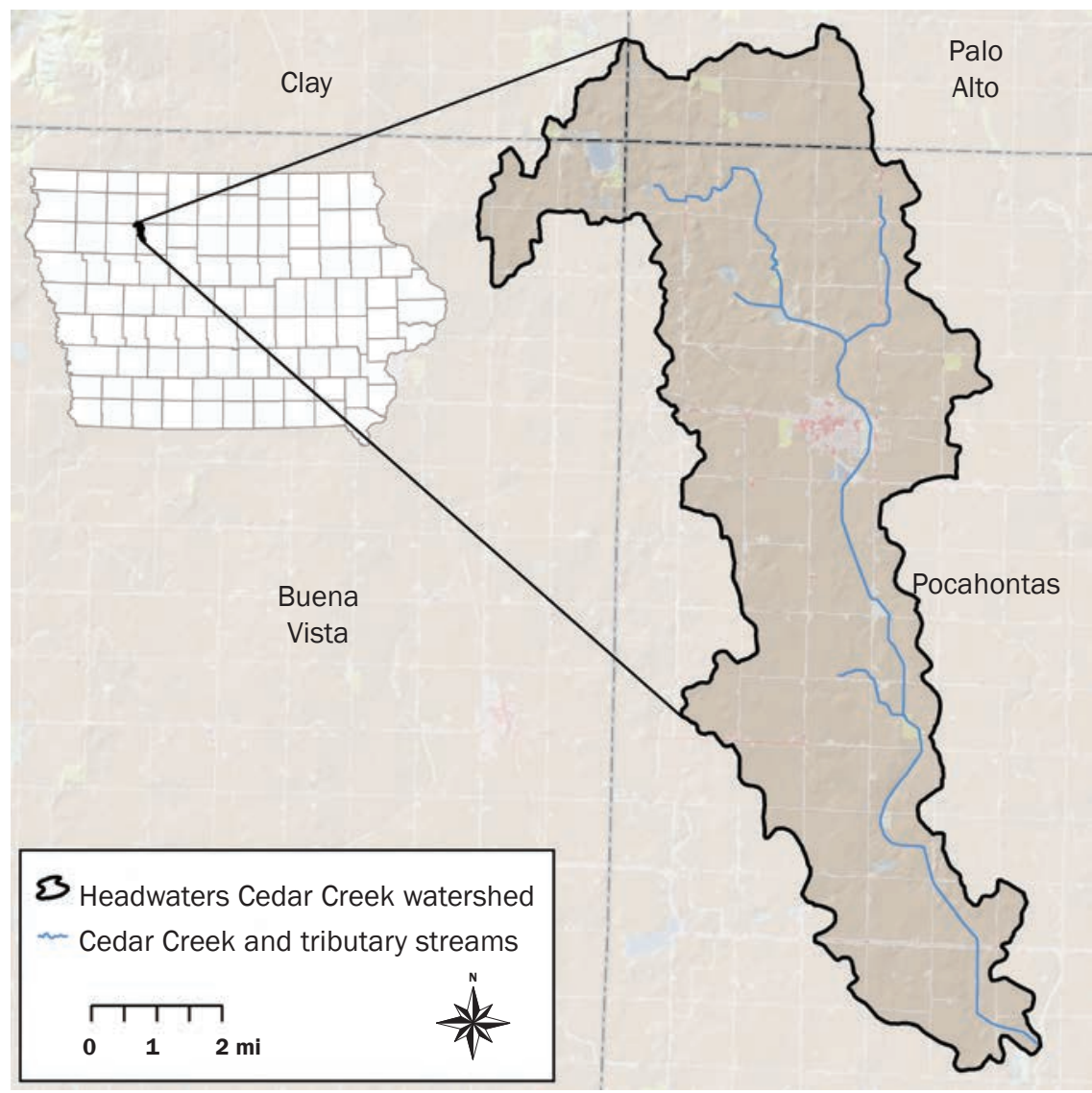


no-till, cover crops, and perennial cover (figure 3). While conceptual, it is key that such recommendations and objectives in watershed plans are based on local social and environmental factors.

Regular engagement with farmers throughout the watershed planning process is critical to integrate goal setting, watershed modeling, and ACPF mapping. Certain criteria must be met to initiate the watershed planning process: local interest in watershed planning, technical capacity to develop a plan, and funding. Typically, the ISA works with farmers, landowners, and additional partners, such as watershed coordinators or soil and water conservation district staff, to identify a specific HUC12 watershed for project planning and development and to secure funding (commonly a private or public grant) to support planning activities. The ISA then coordinates the process and leverages its expertise in geographic information systems, modeling, planning, and meeting facilitation to minimize effort but maximize value for local farmers and partners. For example, ISA conducts ACPF modeling and develops maps, which are then shared with farmers and technical experts to verify that model outputs align with local knowledge of the watershed. The financial and human capital required to support this community-focused approach to watershed planning yields dividends in the form of empowered watershed stakeholders.

Beyond developing local leadership and establishing project schedules and evaluation metrics, watershed plans can enable local watershed groups to secure additional technical and financial assistance, which are critical for sustained implementation of those watershed plans. Experience has shown that investments in watershed planning can yield substantial dividends in the form of technical and financial assistance. For example, the Rock Creek Watershed Plan was developed in 2014 and subsequently has been used by project partners to secure approximately $\$ 1.75$ million through programs including the Iowa Department of Agriculture and Land Stewardship Water Quality Initiative, the USDA Natural Resources Conservation Service Regional Conservation Partnership Program, and additional public and pri-

\section{Figure 3}

Conceptual plan for conservation practice implementation in the Headwaters Cedar Creek watershed. Practices, quantities, and locations were identified by integrating farmer input, the lowa Nutrient Reduction Strategy, and Agricultural Conservation Planning Framework results.

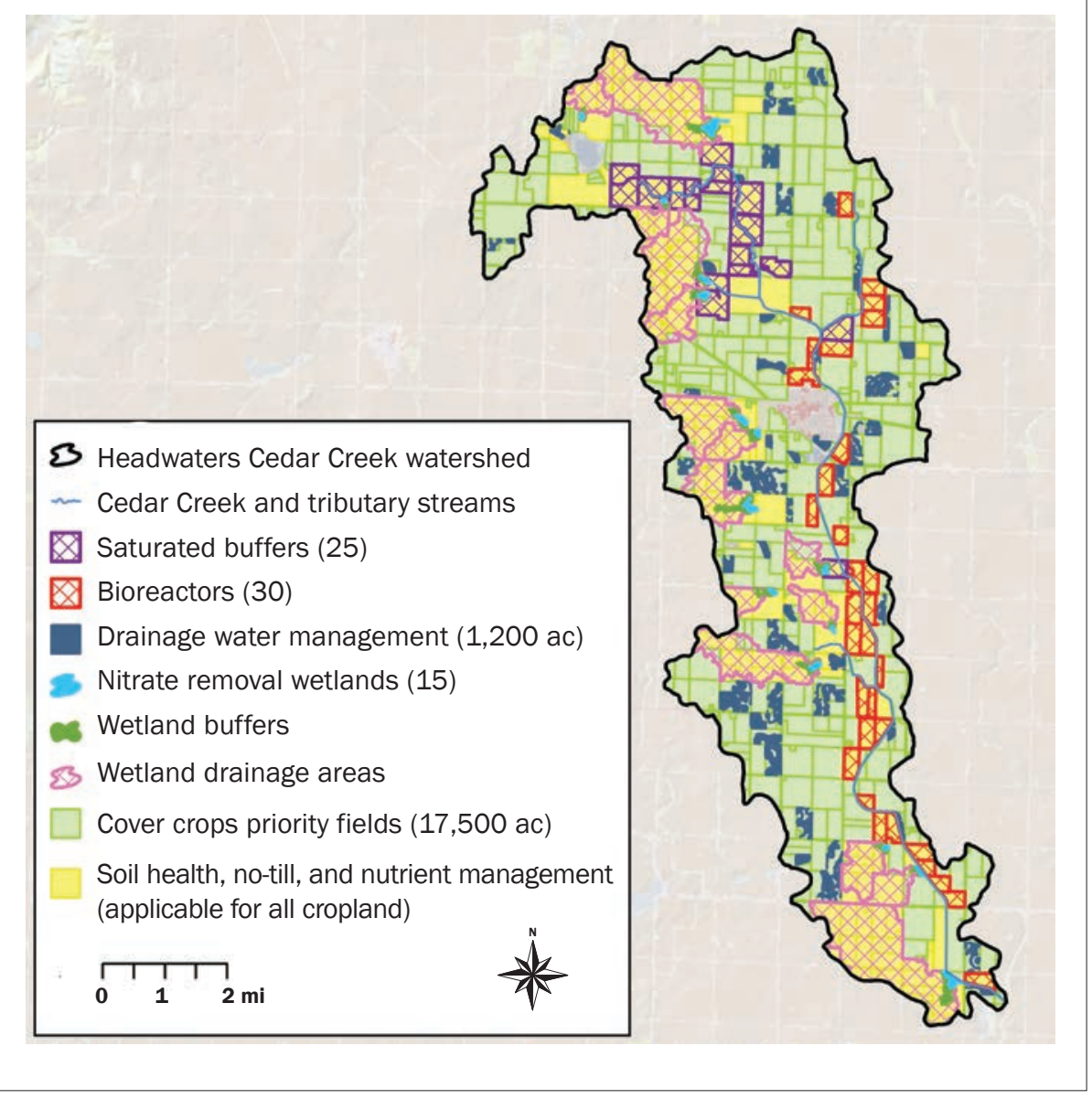

vate sources. The funds have been utilized to support a watershed project coordinator; conservation practice implementation; and associated project costs including water monitoring, outreach, and education.

In addition to involving farmers and landowners in the planning process and helping to secure funding, watershed plans can maximize watershed project impacts during the implementation and evaluation phases by identifying and integrating key priorities (farmer input), objectives (water quality models), and locations (ACPF results) to support progress toward longterm watershed goals. Local watershed improvement and regional nutrient load reduction will derive greater benefit if watershed plans are both people-based and place-based. This straightforward approach that incorporates farmer engagement, the best available science, and feasible conservation sites to develop watershed plans can be deployed across Iowa and the Mississippi River Basin to lay foundations for increased local leadership and accelerated water quality improvement.

\section{ACKNOWLEDGEMENTS}

We are grateful to the Agricultural Conservation Planning Framework (ACPF) development team for consultation, the Iowa Flood Center/IIHR for sharing ACPF data, and Mark Tomer, Ann Lewandowski, and Carol Brown for providing feedback on this article. Our work is partially funded by the soybean checkoff.

\section{REFERENCES}

Beauvais, J. 2016. Renewed Call to Action to Reduce Nutrient Pollution and Support for Incremental Actions to Protect Water Quality and Public Health. Washington, DC: United States 
Environmental Protection Agency. https://www. epa.gov/sites/production/files/2016-09/documents/renewed-call-nutrient-memo-2016.pdf.

IDALS (Iowa Department of Agriculture and Land Stewardship), Iowa Department of Natural Resources, and Iowa State University-College of Agriculture and Life Sciences. 2017. Iowa Nutrient Reduction Strategy.Ames, IA: Iowa State University. http://www.nutrientstrategy.iastate.edu/sites/ default/files/documents/2017\%20INRS\%20 Complete_Revised\%202017_12_11.pdf.

IDNR (Iowa Department of Natural Resources). 2009. Watershed Management Action Plan DNR Guidebook. Des Moines, IA: Iowa Department of Natural Resources. http://www.iowadnr.gov/ portals/idnr/uploads/water/watershed/files/ wmp_guide.pdf.

ISA (Iowa Soybean Association). 2016. Headwaters Cedar Creek Watershed Plan. Ankeny, IA: Iowa Soybean Association. https://www.iasoybeans. com/upl/downloads/publications/headwaterscedar-creek.pdf.

Porter, S.A., M.D. Tomer, D.E. James, J.D. Van Horn, and K.M.B. Boomer. 2018. Agricultural Conservation Planning Framework: ArcGIS Toolbox User's Manual, v. 3.0. Ames, IA: USDA Agricultural Research Service National Laboratory for Agriculture and the Environment. https://acpf4watersheds.org/.

Stoner, N.K. 2011. Working in Partnership with States to Address Phosphorus and Nitrogen Pollution through Use of a Framework for State Nutrient Reductions. Washington, DC: United States Environmental Protection Agency. https:// www.epa.gov/sites/production/files/documents/memo_nitrogen_framework.pdf.

Tomer, M.D., S.A. Porter, D.E.James, K.M.B. Boomer, J.A. Kostel, and E. McLellan. 2013. Combining precision conservation technologies into a flexible framework to facilitate agricultural watershed planning. Journal of Soil and Water Conservation 68(5):113A-120A, doi:10.2489/jswc.68.5.113A.

Tomer, M.D., S.A. Porter, K.M.B. Boomer, D.E. James, J.A. Kostel, M.J. Helmers, T.M. Isenhart, and E. McLellan. 2015. Agricultural Conservation Planning Framework 1: Developing multipractice watershed planning scenarios and assessing nutrient reduction potential. Journal of Environmental Quality 44(3):754-767. https://dl.sciencesocieties.org/publications/jeq/ pdfs/44/3/754. 